\title{
The Universal Periodic Review as Mechanism and Process*
}

The Universal Periodic Review is widely perceived to be a tool of the Human Rights Council (HRC), which meets in Geneva. It is indeed that, but that is not all. It is helpful to consider the UPR both as a mechanism and a process. The mechanism is the part that takes place in Geneva and the process is a much larger and longer project that begins before the Geneva element and extends considerably beyond it.

\section{UPR - the mechanism}

A set of flow charts that simplify the UPR process are included in this publication (Annex 3), as is Resolution 5/1, which sets out the new mechanism (Annex 1). A brief summary should serve as a straightforward run-through and explanation.

The UPR commits the UN, through the HRC, to review every state's record and the challenges it faces in promoting human rights. The review is by peers, rather than by experts steeped in the law, language and mechanics of human rights. Other mechanisms - special procedures - perform this function, so there is no need to recreate these in the HRC. All 192 UN member states must undergo review under the Geneva-based mechanism, with 48 reviewed each year in three batches of 16 - the sequence having been determined through a random selection process. An HRC working group is convened for the UPR, for two weeks, three times a year. Three documents provide a written basis for the review, together with an oral presentation by the state under review (SuR). The heart of the review is a three-hour session, known as the interactive dialogue, in which the SuR speaks to issues raised in the documents and in which any questions previously put to the state can also be addressed. Members of the HRC and observer states may participate in the dialogue, putting questions, making suggestions or raising issues of concern by putting their names on a list.

The SuR is guided and supported through the process by a group of three other states - known as the troika. These are randomly selected states, although they should in principle include one from the region of the SuR, and very few names have been rejected by any SuR. The troika meets with the SuR before and during the review. Together they discuss the process and the troika feeds through any questions or comments from other states that have been submitted in advance of the interactive dialogue. The troika is available to discuss options and responses to recommendations put to the SuR.

*Contributed by Dr Purna Sen, Head of Human Rights, Commonwealth Secretariat. 
The SuR is sovereign in determining which of the suggestions and recommendations made to them they are willing to accept. International standards and norms, recommendations of treaty bodies and other special procedures and other accepted frameworks will together form a strong point of reference for discussions and for anticipated agreement on future work. The UPR is intended to be a review and a collective commitment for action - through the working group discussions other states offer support and advice on the implementation of accepted recommendations. Other organisations, such as the UN, aid agencies and the Commonwealth Secretariat, also make their services and funds available.

The interactive dialogue is followed two days later by the adoption of the report of the dialogue. This document, drawn up by the OHCHR, details the discussions and initial responses of the $\mathrm{SuR}$, as well as recommendations made in the working group. The final step of the mechanism involves consideration of the report of the SuR by the next session of the HRC plenary, at which time the SuR has the opportunity to make a statement and answer questions, and other states can make observations. This is the session at which stakeholders can make oral contributions. This is the point at which the final outcome document of the SuR is adopted; the document includes any voluntary pledges and commitments made by the SuR.

\section{UPR - the process}

The flowcharts in Annex 3 refer to two elements that are not Geneva based: the pre- and post-Geneva periods. As described above, the UPR mechanism forms a technical but significant element in a larger project - that of promoting human rights in member states.

It is through reporting and sharing challenges in this endeavour that greater energy and expertise can be galvanised towards collective efforts to realise human rights. Offers of technical support and co-operation can flow from the mechanism to support the process on the ground. The UN has established trust funds (Annex 4) to assist states where resource constraints limit human rights development work. The follow-up phase, as it is now being seen, is closely linked to the Geneva mechanism, as this is where the accepted recommendations and voluntary pledges to action, as well as offers of support, need to be made real. In time, the follow-up phase will become the preparatory phase as the second round of reporting approaches.

The principle of consultation and co-operation between stakeholders and states applies before and after the Geneva element. In some cases this will be a new approach (see the chapter on the experience of a small state in section 2). In others it will be a set of old relationships that will hopefully be refreshed. Not all such relationships are easy or new, yet it remains possible that they can be made to 
work. Indeed, the UPR may be a useful prompt for the establishment or reconstitution of such relationships. The fact that states have been tasked with undertaking consultation gives them a responsibility; civil society should see this as an opportunity to establish or renew dialogue.

\section{Figure 1. UPR - the process}

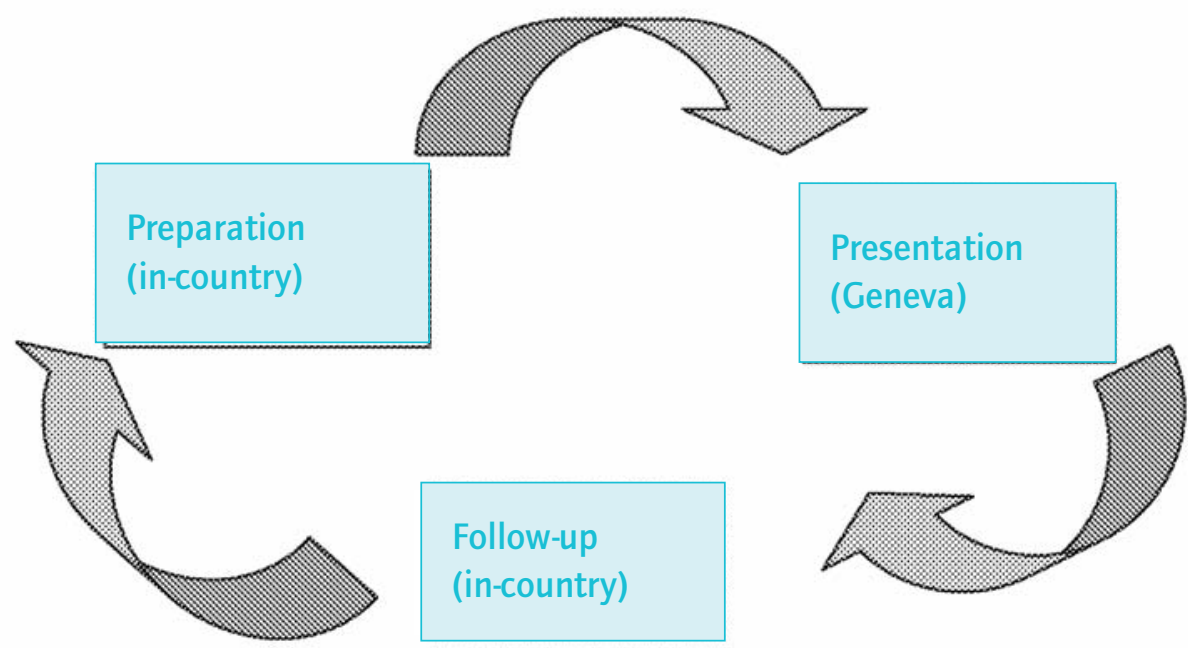

Discussions and consultations within the Commonwealth have acknowledged the difficulties of undertaking a new reporting process: most state departments have not been provided with additional staff for this - nor have NGOs. Moreover, ministries tasked with the compilation of state reports have told of the challenges of coordinating and compiling information for the UPR. It is helpful to see the UPR as a process, as the relationships built in the compilation stage can be revisited in the follow-up phase. After all, it is likely that implementation will require efforts both from a variety of ministries and from stakeholders. 


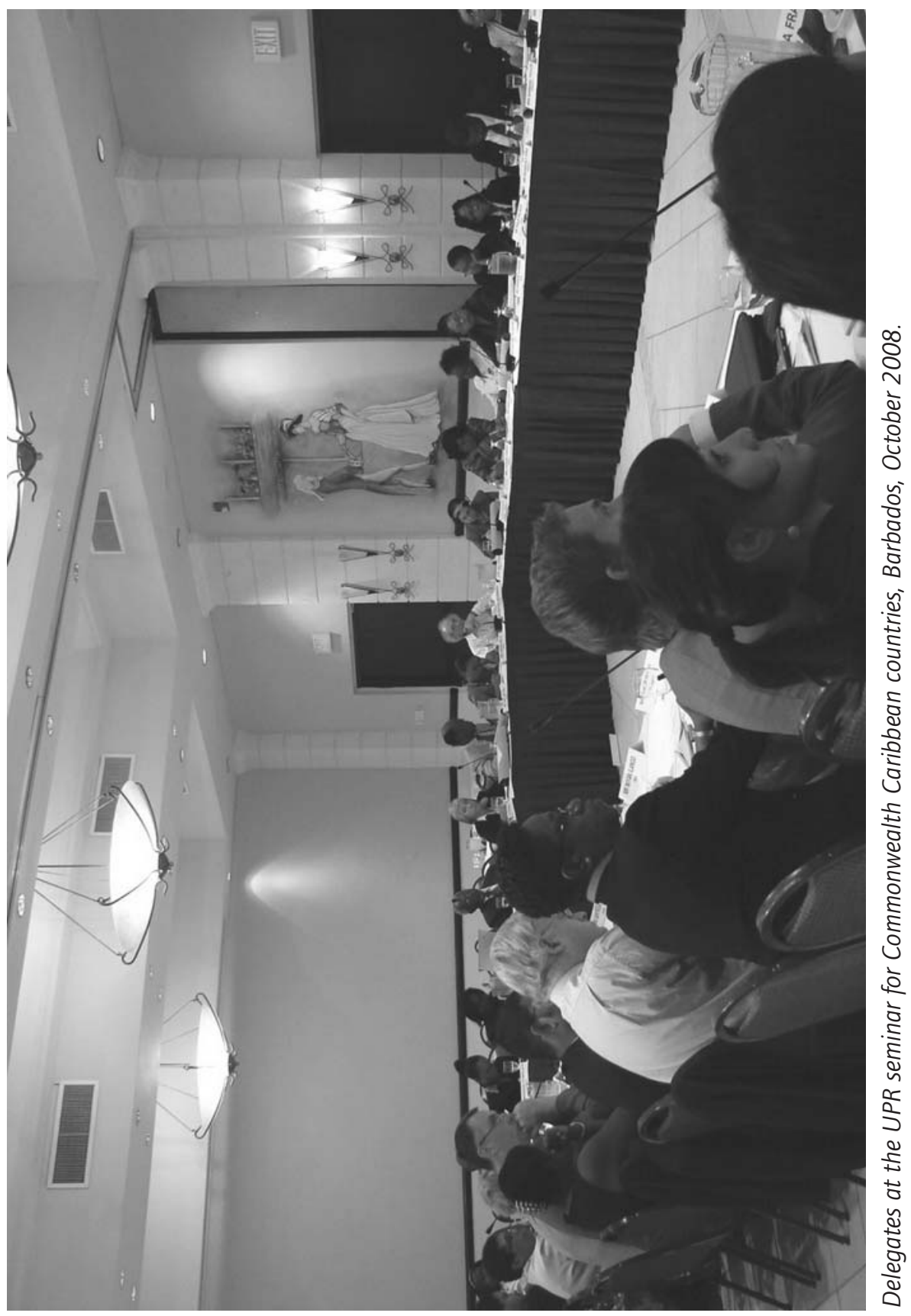

